\title{
Gestão do conhecimento e teoria da firma
}

Antonio Braz de Oliveira e Silva

Doutor em Ciência da Informação (PPGCI/UFMG). Especialista em Economia (IEI/UFRJ). Bacharel em Administração Pública (EBAP/Fundação Getúlio Vargas), analista sênior do IBGE.

Marta Araújo Tavares Ferreira

\begin{abstract}
Doutora em Engenharia Industrial e Gestão da Inovação Tecnológica (Ecole Centrale Paris), Diplomada em Estudos Aprofundados em Economia Industrial (Université Paris IXDauphine), Mestre em Engenharia de Produção (PUC Rio), professora visitante na Universidade de Montreal em 2001, professora adjunta da PUC Minas e professora associada da UFMG.
\end{abstract}

Para uma melhor compreensão da importância da gestão do conhecimento para as empresas, é necessário que se retorne à teoria da firma. As firmas se organizam em estruturas que visam diminuir os custos de obter e trocar informações. Esse artigo discute os impactos das tecnologias de informação (TICs) sobre as firmas. As TICs, por facilitarem a troca de informações entre empresas, afetam os seus limites, abrindo novos campos para a gestão do conhecimento.

Palavras-chave: Teoria da Firma; Gestão do Conhecimento; Cooperação Empresarial.

\section{Knowledge management and theory of the firm}

For a better understanding of the importance of knowledge management for enterprises, it is necessary to consider the theory of the firm. To accomplish their functions, the firms organize themselves in structures that aim at diminishing the costs of obtaining and exchanging information. This paper discusses the role of information technologies in facilitating information and knowledge 
exchange among firms, as they enlarge firms possibilities of cooperation and affect their limits, creating new opportunities to knowledge management.

Keywords: Theory of the Firm; Knowledge Management; Firm Cooperation.

Recebido em 10.07.2009 Aceito em 04.12.2009

\section{Introdução ${ }^{1}$}

O economista Ronald Coase, ao tratar das instituições em sua aula magna durante cerimônia de entrega do Prêmio Nobel de Economia, destacou que os economistas tratam as firmas como 'caixas-pretas', por não se interessarem pela sua estrutura interna de funcionamento, mas apenas pelos mercados, pelas compras dos fatores de produção e pela venda dos bens produzidos com o uso desses fatores:

isso é extraordinário uma vez que a maior parte dos recursos em um sistema econômico moderno são empregados pelas firmas, e como esses recursos são usados depende de decisões administrativas e não, diretamente, das operações de um mercado. Conseqüentemente, a eficiência do sistema econômico depende, de uma maneira bastante considerável, de como essa organização conduz os seus negócios, em particular as grandes empresas modernas (COASE, 1991, [s.p.]).

Numa economia capitalista moderna, a maior parte da produção de riquezas é feita pelas empresas. A teoria que se ocupa da produção, na literatura econômica, é denominada 'teoria da firma', embora englobe abordagens teóricas bastante diferentes, uma vez que não se produziu uma definição clara e amplamente aceita da firma (KERSTENETZKY, 1995).

Neste artigo, os termos 'firma' e 'organização' e, em menor grau, 'empresa', serão usados, em várias ocasiões, como sinônimos. As firmas são organizações com uma hierarquia, divisão do trabalho e uma estrutura de gerência executiva que planeja e decide sobre as questões que afetam o seu desenvolvimento (KERSTENETZKY,1995).

O objetivo do artigo é assinalar a relevância de se fazer a discussão das práticas denominadas 'Gestão do Conhecimento', tendo como pano de fundo uma base teórica - a Teoria da Firma. Como ela engloba

${ }^{1}$ O presente artigo é parte da pesquisa doutoral do autor, orientado pela $\operatorname{Prof}^{\mathrm{a}} \mathrm{Dr}^{\mathrm{a}}$. Marta Araújo Tavares Ferreira, realizada para estudar o cluster da construção em Minas Gerais (SILVA, 2007). Tese apoiada pelo programa de capacitação de servidores da Fundação Instituto Brasileiro de Geografia e Estatística (IBGE). Os autores agradecem as valiosas sugestões dos avaliadores, importantes tanto para a melhoria do conteúdo quanto para avanços futuros. 
abordagens teóricas distintas, foram analisadas aquelas que definiram os principais programas de pesquisa ${ }^{2}$ sobre o tema.

A metodologia empregada foi a revisão bibliográfica da literatura clássica sobre o tema, complementada pela leitura de artigos e teses nacionais, em especial aquelas associadas à Gestão do Conhecimento.

O presente artigo, além dessa introdução, está organizado em seis seções temáticas e uma final, a sétima, de conclusão. Na seção 1 , apresenta-se a teoria neoclássica da firma e suas limitações, para em seguida apresentar os questionamentos que possibilitaram o surgimento de um programa de pesquisa distinto do programa neoclássico - a Economia dos Custos de Transação. Na seção 2, apresentam-se alguns conceitos fundamentais da abordagem realizada por Penrose (1959), que pode ser considerada uma abordagem complementar aos custos de transação e, ao mesmo tempo, referência para a abordagem analítica denominada 'Visão da Firma Baseada em Recursos' (Resource-Based-View of The Firm - RBV). Na seção 3, as idéias básicas da teoria evolucionária da firma são discutidas. A seção 4 associa as teorias da firma apresentadas com a evolução das empresas ao longo do último século e suas consequências sobre as técnicas de gestão, desembocando na seção 5 , que trata das práticas de gestão do conhecimento, surgidas no final do século XX. A seção 6 associa as novas tecnologias de informação e comunicação baseadas na microeletrônica com a teoria da firma (no caso, os limites da firma) e com a gestão do conhecimento.

Observe-se que não houve intenção de explorar neste artigo as diferenças existentes entre os programas de pesquisa sobre a firma. Também não se pretendeu analisar a evolução recente de algumas abordagens, como a RBV, que vêm sendo cada vez mais utilizadas nos estudos sobre o comportamento estratégico das empresas (COELHO, PAVÃO, BANDEIRA-DE-MELLO, 2009). Ressalte-se, ainda, que para os objetivos aqui apresentados, o recente trabalho de Pitelis e Teece (2009), que propõe que o objetivo, a natureza e a essência da firma podem ser tratados indistintamente, traria uma linha de desdobramento mais atraente, especialmente por trazer para o centro da teoria a inovação, o que levaria a se discutir, na mesma linha deste artigo, a gestão da inovação ${ }^{3}$.

\section{A firma neoclássica e a firma na economia dos custos de transação}

Na teoria neoclássica, a firma é tratada de uma forma mais ou menos abstrata e seria, apenas, o local que reúne fatores de produção

\footnotetext{
${ }^{2}$ Conforme Lakatos (1979), em suas reflexões sobre o desenvolvimento da ciência, o autor afirma que o progresso científico se encaminha por meio do que ele conceitua como 'programas de pesquisa'. Programas de pesquisa, em linhas gerais, são diretrizes metodológicas responsáveis pela decisão acerca da construção e modificação das teorias. Lakatos sustenta que programas de pesquisa científica devem ser constituídos por um "núcleo firme" (hard core) - central, axiomático e irrefutável - e por um "cinturão protetor" (protective belt) - mutável e refutável.

${ }^{3}$ Nessa linha, sem entrar na discussão sobre a essência e a natureza da firma, Marins (2007) discute a Gestão Tecnológica tendo como referência a Teoria da Firma.
} 
(capital e trabalho) que se combinam de acordo com a tecnologia disponível e de conhecimento comum, comportando-se, assim, como um ator passivo, que toma a tecnologia, os preços dos fatores e a capacidade organizacional como dados. Aspectos organizacionais ou de relacionamento com clientes e fornecedores são ignorados. A natureza da firma com respeito às suas decisões de produção e de investimento, bem como os aspectos de organização interna, tais como a estrutura hierárquica e os processos de controle, por exemplo, são irrelevantes (FEIJÓ, VALENTE, 2004). Nessa teoria, o sistema de preços da economia funcionaria como um sistema de informações, totalmente adequado a um regime no qual as firmas e os consumidores têm amplo conhecimento das variáveis relevantes para processar suas escolhas.

Mudanças ocorridas na teoria da firma buscaram introduzir aspectos de comportamento mais próximos daqueles verificados na realidade, destacando os processos de tomada de decisão e incorporando outros objetivos, além da maximização do lucro, nos procedimentos de análise. Nessas abordagens, as firmas são descritas a partir de suas atribuições básicas de produção e das rotinas a ela associadas. Suas relações com outras firmas são reguladas por contratos, o que levou ao questionamento, por parte de alguns economistas, dos mecanismos de mercado e dos sistemas de preços como suficientes para coordenar a produção de bens e serviços.

Marshall (1982), um dos economistas mais referenciados sobre a teoria da firma, considerava que esta, longe de ser uma entidade teórica e distante da realidade, interagia e interferia no ambiente, e sofria suas influências, ou seja, a firma marshalliana era um agente ativo e não apenas reativo às mudanças externas (FEIJó, VALENTE, 2004).

Marshall (1982) também considerava relevante analisar o trabalho da administração da empresa e entender por que suas diferentes formas produzem resultados distintos, já que "[...] umas são mais aptas a tirar partido do meio ambiente e de prevalecer sobre outras" (MARSHALL, 1982, p. 229). Ele, assim como Adam Smith, entendia que o aumento da eficiência do trabalho está relacionado à sua organização e divisão (MARSHALL, 1982). O capital era por ele considerado como muito mais que simplesmente o capital físico representado pela maquinaria. Segundo ele:

O capital consiste, em grande parte, em conhecimento e organização: desta, uma parte é propriedade privada, outra não. O conhecimento é nossa mais potente máquina de produção: habilita-nos a submeter a Natureza e forçá-la a satisfazer nossas necessidades. A organização ajuda 0 conhecimento; ela apresenta muitas formas, a saber, a organização de empresas individuais, a de várias empresas num mesmo ramo, a de vários negócios uns relativamente aos outros, e a organização do Estado provendo segurança para todos e ajuda para muitos. A distinção entre propriedade pública e propriedade privada, no que se refere ao conhecimento e à organização, é de grande e crescente 
importância, sob certos aspectos, de importância maior do que a mesma distinção, do ponto de vista das coisas materiais. Em parte por essa razão, parece por vezes melhor admitir a organização como um agente de produção à parte e distinto (MARSHALL, 1982, p. 135).

Assim, o conceito de firma de Marshall considera vários fatores hoje presentes na literatura em gestão, tais como conhecimento e organização. A organização eficiente da indústria se relaciona à habilidade de direcionar os empregados aos trabalhos para os quais demonstrem maior capacidade e preparo, e à disposição da melhor maquinaria e instrumentos, isto é, capital físico adequado e moderno. As vantagens da divisão do trabalho seriam mais bem aproveitadas nas grandes empresas, isto é, se relacionariam positivamente com a concentração de capitais; e o aumento de escala das empresas traria mais oportunidades de divisão do trabalho também no terreno da administração (MARSHALL, 1982).

Os aumentos da produtividade relacionados ao aumento na escala foram divididos em duas classes: as economias externas, dependentes do desenvolvimento geral da indústria (das vantagens da maior concentração de firmas similares numa mesma localidade), e as economias internas, dependentes dos recursos de cada empresa individual e relacionadas à sua organização, à eficiência de sua administração e aos processos de produção.

As vantagens da escala relacionam-se, também, àquelas obtidas nas compras, comercialização, propaganda, acesso ao crédito e ao financiamento dos riscos associados à inovação. No entanto, para chegar a esse estágio, a firma passa por um processo de crescimento que envolve sua capacitação em várias áreas (de produção, administração, comercialização e inovação) e o desenvolvimento de uma rede de relações comerciais.

Coase (1937) trouxe uma nova abordagem sobre a firma, que possibilitou o surgimento de um programa de pesquisa distinto do programa neoclássico. Ele partiu da simples questão: porque as firmas existem? E foi a resposta a essa pergunta que, justamente, levou Ronald Coase ao reconhecimento pela Academia Real de Ciências da Suécia. Segundo Granovetter (1994), ao se colocar essa simples e inócua questão, que pode ter ocorrido a outros, mas não havia sido objeto de uma investigação sistemática, ele começou uma revolução silenciosa.

Em sua resposta, agora famosa, e grandemente elaborada por Oliver Williamson numa série de trabalhos que divulgaram o seu programa de pesquisas sobre mercados e hierarquias, as firmas existem em função da presença de custos de transação e porque o sistema de preços não pode prover toda a informação requerida em cada transação no mercado (GRANOVETTER, 1994).

De maneira simplificada, para Coase (1937) os custos de se obter informações e controlar os contratos são minimizados no interior das firmas. As escolhas entre produzir internamente ou comprar no mercado seriam feitas no interior de uma estrutura hierárquica, com os gerentes respondendo às forças do mercado e balanceando constantemente o custo de usar o mercado com o custo da organização interna. Assume-se, assim, a possibilidade de se 
medir tais custos de forma inequívoca e sistemática, mesmo num ambiente de incerteza, informação incompleta e inovação.

Os limites da firma passam a ser dados pela escolha entre quais atividades devem ou não ser realizadas internamente, ou seja, entre 'fazer ou comprar' (KERSTENETZKY, 1995; FEIJÓ; VALENTE, 2004). Em outras palavras, existem custos associados ao uso dos mecanismos de preços, tais como obter informações, escrever e controlar contratos, acompanhar as transações no mercado, etc. Assim, em alternativa ao sistema de preços como mecanismo de coordenação, a firma se coloca como uma instituição hierárquica, na qual a alocação de recursos é resultado de decisões administrativas:

os empresários, ao decidirem sobre a condução dos negócios e sobre o que produzir, levam em conta os custos de transação. Se os custos superam os ganhos [...] não haverá produção. Dessa forma, os custos de transação afetam não apenas os arranjos contratuais, mas também quais bens e serviços serão produzidos (COASE, 1991, [s.p.], tradução nossa).

Além dos custos de transação, a incerteza é um elemento relevante para a existência da firma (KNIGHT, 1971 apud KERSTENETZKY, 1995). A assimetria de informação gera conhecimentos distintos sobre as oportunidades de negócios que são exploradas por firmas, enquanto as vantagens são obtidas pelo controle e pelo gerenciamento dos processos de produção associados a essas oportunidades. Ainda assim, os riscos são grandes, pois as decisões são tomadas com base em conhecimentos construídos a partir de informações parciais. A firma surge e se especializa de "forma a assegurar maior conhecimento e algum controle sobre 0 futuro" (KERSTENETZKY, 1995, p. 48). Dessa forma, a firma é uma organização cuja origem está diretamente associada à busca de informação e conhecimento.

Williamson e seus seguidores, nos anos 1970 e 80, procuraram elaborar a abordagem dos custos de transação de Coase. Williamson (1975) criticou os pressupostos neoclássicos e introduziu a noção de firma como uma 'estrutura de governança', propondo o conceito de especificidades dos ativos, sendo que essas especificidades afetariam as relações entre firmas. Segundo esse autor, a firma se define num contexto de racionalidade limitada (bounded rationality) e de oportunismo dos agentes (self-interest seeking with guide), e os custos de transação interfeririam na escolha entre fazer internamente (em função das especificidades dos ativos, garantindo a seu proprietário se apropriar de todo o retorno econômico) ou comprar no mercado (pagar pelo uso de ativos de terceiros) (KERSTENETZKY, 1995); ou, nas palavras de Williamson, "a economia dos custos de transação sustenta que economizar nos custos de transação é o principal determinante na escolha de uma forma de organização capitalista sobre a outra" (WILLIAMSON, 1995, p. 223, tradução nossa).

Muitas críticas são feitas aos trabalhos de Williamson e seus seguidores, uma vez que podem existir arranjos intermediários entre internalizar a produção e a aquisição no mercado, como pode ser 
observado, por exemplo, pela existência de redes de cooperação entre empresas ou pela associação de firmas, motivadas pela redução de riscos, para a realização de investimento conjunto em inovações (KERSTENETZKY, 1995).

\section{3 o conhecimento no paradigma alternativo da teoria da firma}

De acordo com Pavitt (2001), Edith Penrose foi um dos poucos eminentes economistas do século $X X$ a considerar que aquilo que acontece dentro das firmas é importante para a economia, desenvolvendo uma abordagem inovativa e extremamente importante sobre o tema. Penrose (1959) considera útil o conceito de rotinas organizacionais e reconhece que muito do conhecimento fundamental para a diversificação e crescimento da firma existe em sua forma tácita e é aprendido pela experiência.

O trabalho de Penrose pode ser visto como "a base sobre a qual se assenta boa parte dos esforços contemporâneos de constituição de um paradigma alternativo para a teoria da firma" (KERSTENETZKY, 1995, p. 52). Segundo Pitelis e Teece (2009), ...

... a teoria do crescimento da firma de Penrose (1959) pode ser considerada como uma abordagem alternativa e complementar à economia dos custos de transação. Ela, indiretamente, responde à pergunta sobre por que as firmas existem ao recorrer aos custos de produção e aos aumentos de receita (revenue enhancing) no lugar da redução dos custos de transação (PITELIS; TEECE, 2009, p. 5, tradução nossa).

Segundo Penrose (1959), a firma só pode ser definida em função do que ela faz ou do que é feito nela. A função econômica básica da firma é fornecer os bens e serviços demandados, com a utilização de recursos produtivos de acordo com os planos desenvolvidos em seu interior. Portanto, a firma planeja, e suas diferentes atividades internas e os departamentos são coordenados pela existência de uma política que é desenhada ao se pensar na firma como um todo, isto é, segundo a estratégia definida para o negócio (PENROSE, 1959).

Penrose foi a primeira autora a conceber uma análise da firma centrada em suas capacidades (organizational capabilities), ou seja, a firma é tanto uma organização administrativa quanto uma coleção de recursos produtivos. Em sua análise, a autora distingue os 'recursos' dos 'serviços dos recursos'. Recursos podem ser definidos independentemente do seu uso, enquanto os serviços providos pelos recursos não podem. Portanto, inputs não são simplesmente fatores de produção. Eles são serviços de fatores para a firma, de forma que as características produtivas destes serviços são determinadas pelo contexto organizacional 
no qual são usados, isto é, eles são específicos para cada firma (FEIJÓ; VALENTE, 2004).

A firma é uma organização e os recursos que ela administra, inclusive os gerenciais, são os fatores que impulsionam 0 seu crescimento; mas este é limitado pelo tempo e pela capacidade de se adquirir novos conhecimentos. Os recursos gerenciais são específicos e neles estão depositados os conhecimentos e a experiência da firma. Penrose (1959) introduz o conceito de equipe de trabalho (teamwork), destacando a importância do conhecimento tácito, da confiança e das redes. A autora destaca, ainda, o papel da incerteza no desenvolvimento da firma e a importância dos recursos e dos serviços gerenciais, chamando a atenção, também, para a associação entre incerteza e informação:

incerteza refere-se à confiança do empresário nas suas estimativas ou expectativas. Risco, por outro lado, refere-se aos possíveis resultados da ação, especificamente à perda que possa ocorrer se uma determinada ação for tomada (PENROSE, 1959, p. 56, tradução nossa).

Essa afirmação se completa quando a autora aponta que umas das formas mais importantes de se reduzir a incerteza sobre o desenrolar futuro dos acontecimentos é obtendo mais informações sobre os fatores relevantes; e uma das tarefas mais importantes da firma, num mundo de incertezas, é obter o maior volume possível dessas informações. Para obtê-las, são necessários maiores recursos, enquanto que para interpretálas, são necessários 'serviços gerenciais' ('services of existing managemet'). A combinação dos recursos com a capacidade de interpretação foi denominada, pela autora, de 'pesquisa gerencial' ('managerial research') (PENROSE, 1959).

A concepção da firma de Penrose adianta uma série de atributos que, atualmente, são amplamente destacados na literatura sobre gestão. Sem ordem de importância, pode-se mencionar, em primeiro lugar, a necessidade de se pensar que a firma pressupõe o trabalho em equipe (teamwork), que demanda tempo para ser constituída e para ser, progressivamente, incrementada. Em segundo lugar, o crescimento da firma está associado à acumulação de conhecimento em seu interior, e está sob o controle de suas equipes. Sendo assim, destaca-se um terceiro elemento relacionado ao conhecimento tácito dos membros da equipe e ao aprendizado organizacional: o conhecimento nascido da experiência é central e todo gerente tem qualificações práticas e conhecimentos técnicos que não são facilmente codificados.

A teoria da firma de Penrose é, portanto, uma 'teoria da firma que aprende' (learning theory of the firm), visto que, na sua concepção, não só produtos e serviços são produzidos, mas também conhecimentos (FEIJÓ; VALENTE, 2004). 
Penrose destaca a importância da cultura organizacional - interação de crenças e compromissos partilhados que são reforçados por ações numa base diária -, que se constitui na matéria-prima do teamwork. Conseqüentemente, as firmas são instituições sociais com cultura única, um conceito que não consta da economia neoclássica (FEIJó; VALENTE, 2004); e "as combinações de recursos no interior da firma se dão segundo padrões estabelecidos pelo conhecimento comum aos seus membros" (KERSTENETZKY, 1995, p. 57).

As capacidades das firmas podem explicar o agrupamento de atividades distintas em seu interior, assim como a existência da cooperação entre elas. Elas têm a tendência de desenvolver, internamente, atividades similares baseadas em suas capacidades e, também, de construir uma rede comercial para dispor de bens e serviços de atividades complementares. A complementaridade aponta, ainda, para uma forma de cooperação que envolve a necessidade de coordenação prévia dos investimentos e do desenvolvimento de novos produtos, dividindo os riscos de cada participante (RICHARDSON, 1972 apud KERSTENETZKY, 1995). Essa concepção oferece uma base teórica adicional para os trabalhos empíricos (por exemplo, DeBRESSON, 1996; 1999) que investigam a idéia de que qualquer inovação é, obrigatoriamente, fruto da cooperação.

A definição de capacidades, ou competências, como sendo a combinação de 'conhecimento, experiência e habilidades' ('knowledge, experience and skills'), é um tanto vaga, mas deve ser a capacidade da firma de resolver os problemas que surgem (RICHARDSON, 1972). As capacidades compreendem o resultado da combinação dinâmica dos conhecimentos tácitos e explícitos, e as vantagens da firma estariam relacionadas ao uso do conhecimento acumulado para o aprendizado e a geração de novos conhecimentos, criando, assim, novas competências.

A divisão do trabalho - interna e entre diferentes firmas - surge como uma decorrência desse processo. No interior da firma, cada indivíduo tem apenas uma parcela do conhecimento a ser utilizado na solução de um problema, mas a equipe detém o conhecimento completo necessário para a tarefa. O aprendizado resultante da solução do problema afeta as competências individuais, mas dependente da composição da equipe, ou seja, da divisão interna do trabalho e dos processos internos à equipe. As competências organizacionais seriam 0 resultado desses processos internos, combinados com a aprendizagem decorrente da divisão do trabalho entre firmas, isto é, das redes nas quais cada uma está envolvida (RICHARDSON, 1972 apud KERSTENETZKY, 1995).

Segundo Pitelis e Teece (2009), a Visão da Firma Baseada nos Recursos (RBV) se remete, dentre outros, ao trabalho de Edith Penrose (1959). Segundo esses autores, a contribuição recente da RBV tem como objetivo central o entendimento das vantagens competitivas das empresas, mas não busca explicar a natureza da firma; enquanto a versão da RBV de Penrose pode ser interpretada como uma teoria da essência e da natureza da firma. Assim, as vantagens das firmas sobre os 
mercados, no que diz respeito à criação de conhecimento e à capacidade de inovação, podem ser estabelecidas no interior da Economia dos Custos de Transação. Essa complementaridade, segundo os autores, é admitida pelo próprio Coase . $^{\text {. }}$

\section{A teoria evolucionária da firma, as rotinas e o conhecimento tácito}

A teoria evolucionária da firma, que tem no trabalho de Nelson e Winter (1982) um marco, busca analisar as respostas das firmas e da indústria às mudanças no seu ambiente, em função de alterações no seu próprio mercado, do crescimento econômico e da introdução de inovações. Segundo os autores, as firmas são tratadas a partir de suas capacidades e de seu comportamento anterior, mas o conjunto de regras de decisão, tomado como referência na análise, não pertence à teoria econômica neoclássica (NELSON; WINTER, 1982). Na verdade, essas regras são os padrões de comportamento normais e previsíveis ou, em outras palavras, 'rotinas':

Nós usamos esse termo [rotina] para incluir características das firmas que variam de rotinas técnicas bem especificadas para produzir bens passando por procedimentos para contratar e demitir, administrar o estoque ou incrementar a produção de bens com alta demanda até políticas relacionadas ao investimento, pesquisa e desenvolvimento (P\&D), ou estratégias de negócios e propaganda sobre diversificação de produtos e investimentos no estrangeiro. Na nossa teoria evolucionária as rotinas executam os mesmos papéis que os genes na teoria biológica da evolução (NELSON; WINTER, 1982, p.14, tradução nossa).

Ao destacarem o papel das rotinas como um mapa genético, os autores reconhecem que elas apontam para um possível comportamento (ou, ao menos, indicam a capacidade de se adotar esse comportamento), mas não de forma determinista, uma vez que existem as influências do ambiente. As rotinas podem ser transmitidas, indicando que 0 comportamento de amanhã é determinado pelas rotinas correntes e que elas podem ser usadas na reprodução dos processos em uma outra planta industrial, por exemplo. As firmas e suas rotinas são, também, alvos de seleção, já que umas executam melhor que outras as suas funções (NELSON; WINTER, 1982).

Não se trata de considerar que todas as tarefas de decisão sejam rotineiras. Os processos de tomada de decisão da alta administração estão

\footnotetext{
4 "Such issues notwithstanding, the alleged production costsrelated advantages of firms have been acknowledged as complementary to his own by Coase himself. In a letter to one of the authors about Penrose's views Coase observed that, 'I do not regard her views as an alternative view to mine in The Nature of the Firm but as a necessary addition to it" (PITELIS; TEECE, 2009, p. 8).
} 
longe de serem rotineiros, mas o que é regular e previsível pode ser classificado como rotina.

Para melhor caracterizar os processos rotineiros relevantes para o desempenho da firma, os autores introduzem o conceito de heurística. Uma heurística seria "qualquer princípio ou dispositivo que contribui para a diminuição, na média, [dos procedimentos] de busca por soluções" (NEWELL; SHAW; SIMON, 1962, p. 85, grifo do autor, apud NELSON; WINTER, 1982, p. 132, tradução nossa). Assim, as regras e dispositivos que indicam a qualquer empregado como resolver certos tipos de problemas são heurísticas gerenciais para a solução de problemas (managerial problem-solving heuristic).

As decisões da alta administração não são rotineiras em seus resultados, mas seguem uma heurística - "a heurística fundamental e imperativa para os executivos é desenvolver a estratégia" (NELSON; WINTER, 1982, p. 133, tradução nossa). Da mesma forma, a introdução de uma inovação - um novo bem ou processo - não é algo rotineiro, mas as rotinas de pesquisa em tecnologia o são e possuem uma estrutura simples: seleção do elemento, teste dos atributos desejados, conclusão com sucesso se os atributos estão presentes ou seleção de novo elemento, em caso contrário (NELSON, WINTER, 1982, p. 132).

A firma usa as mesmas rotinas até que se tenha algum motivo para alterá-las. Elas podem, por exemplo, fornecer resultados insatisfatórios. Nesse caso, uma outra área da empresa pode possuir rotinas para identificar essas anomalias no comportamento da área em questão. Por exemplo, caso as vendas em determinada região estejam caindo e isso seja comprovado pelo departamento de vendas, a identificação das causas dessa queda é, geralmente, uma rotina do departamento de pesquisa de marketing (NELSON; WINTER, 1982). Alternativamente, a firma pode, de tempos em tempos, se engajar na análise de suas rotinas com a intenção de melhoria, revisão ou mesmo alterações radicais. Nesse caso, normalmente se recorre à figura de um consultor externo, já que as rotinas existentes estão incrustadas (embedded) nos empregados, o que dificulta sua avaliação pelos envolvidos diretamente na execução (NELSON; WINTER, 1982).

As rotinas da firma são, em grande medida, parte do conhecimento tácito de seus membros, "não sendo transferível por meios formais, e compondo o caráter idiossincrático da atividade empresarial" (KERSTENETZKY, 1995, p. 61). O conhecimento das rotinas é fundamental para o funcionamento da firma, pois uma grande parte do conhecimento necessário para o desempenho do negócio não se encontra registrado em manuais, documentos ou, ainda, no desempenho das máquinas e equipamentos. As rotinas funcionam como uma forma de armazenamento de conhecimento, que é recuperado durante a sua execução. As rotinas são lembradas por seus usos (remembered by doing), e o custo de registrar todas as rotinas, supondo ser possível articular todo 0 conhecimento tácito existente, tornaria a empreitada impraticável. As escolhas apresentadas aos funcionários, em cada momento de sua atuação, são condicionadas pelas rotinas e, portanto, são escolhas 
contidas em um menu reduzido em seu escopo. Mesmo em caso de anomalias de maior impacto, que levam à introdução de inovações, os procedimentos são condicionados por rotinas existentes (NELSON; WINTER, 1982).

O que foi exposto até aqui aponta a importância da escola de pensamento econômico, representada pela teoria evolucionária, para a análise da firma do ponto de vista dos seus processos de gestão. Como uma parte do conhecimento sobre o funcionamento do negócio é tácito e reside nas mentes dos seus empregados e nas rotinas da firma, todas as políticas de armazenamento e recuperação da informação e do conhecimento envolvem a compreensão de como os agentes econômicos selecionam e acumulam os conhecimentos úteis à sua atividade produtiva. Essa acumulação não é um processo apenas individual, mas, principalmente, social: os indivíduos têm capacidade de conhecer apenas uma parcela daquilo que é necessário para os negócios da firma.

Alterações no ambiente afetam o funcionamento das rotinas e subrotinas da firma, e sua adaptação à nova situação depende de heurísticas desenvolvidas internamente ao longo de sua trajetória, relacionadas a procedimentos que lograram êxito no passado. As informações oriundas do ambiente externo são processadas diferentemente por cada firma que participa do negócio. O novo conhecimento criado pela interpretação das informações depende da trajetória de cada firma (path dependence) e da combinação dos conhecimentos tácitos e das heurísticas desenvolvidos pela firma.

As rotinas são, ainda, normas que definem a aplicação de sanções e prêmios, afetando os aspectos cognitivos dos empregados. Por serem mecanismos de controle, regulam as relações dos indivíduos entre si e com as estruturas da organização, inclusive com a hierarquia. Assim, evitam ou previnem o confronto diruptivo, e o funcionamento das organizações é, então, resultado da trégua existente entre seus membros.

As rotinas permitem o surgimento de uma cultura simbólica única e compartilhada pelos membros da organização, que indica os caminhos a serem adotados para mudanças, ao mesmo tempo em que permite a manifestação da defesa dos diversos interesses existentes (NELSON; WINTER, 1982). Assim, existe um processo permanente de escolha entre a necessidade de mudar e a defesa dos interesses constituídos, que molda a forma pela qual a empresa se adapta ao ambiente.

\section{A teoria da firma e o desenvolvimento da moderna administração}

As abordagens da teoria da firma caminharam no sentido de introduzir elementos de realidade e de complexidade na análise da firma, diferentemente da tradição da economia neoclássica. A compreensão da importância da firma para o desenvolvimento implica em analisá-la como unidade autônoma de decisão, isto é, com o poder de fazer escolhas e definir comportamentos ad hoc frente a seu ambiente. 
As firmas tornam-se organizações idiossincráticas, que enfrentam desafios diferenciados e tomam decisões com base em conhecimentos próprios e modos de agir específicos (FEIJó; VALENTE, 2004). Elas desenvolvem funções de produção, pela combinação de fatores de forma eficiente, geram e acumulam conhecimentos, além de estabelecerem laços com outras firmas, e suas interações originam novas estruturas institucionais (KERSTENETZKY, 1995).

A introdução de realismo na análise da firma tem, também, um componente histórico. As alterações sofridas nas economias capitalistas ao longo dos últimos duzentos anos trouxeram novas formas de organização da produção e de funcionamento dos mercados.

De uma perspectiva histórica, o surgimento de novas escolas de administração pode ser associado ao desenvolvimento e aos ciclos de negócios resultantes de novos paradigmas técnico-econômicos. Chandler, um historiador econômico que deixou influências marcantes nas disciplinas de administração, identificou o advento da produção em massa como uma nova forma de organização do capitalismo, ao analisar a economia americana na virada do século $X I X$ para o século $X X$, período da segunda Revolução Industrial. Com as ferrovias e as grandes empresas industriais, introduziu-se uma série de modificações nos processos administrativos decorrentes da organização da produção, como, por exemplo, a verticalização da produção A administração das ferrovias, que funcionavam em grandes extensões territoriais, introduziu a necessidade de administração da logística, usando intensamente as tecnologias de informação e comunicação mais modernas disponíveis - como o telégrafo. Nas grandes empresas localizadas nas indústrias mais modernas, por exemplo nas atividades de produção de equipamentos elétricos, surgiram os primeiros laboratórios de $P \& D$, com o recrutamento de cientistas e engenheiros nos institutos de tecnologia das universidades e nos departamentos de marketing (CHANDLER, 1998a).

No mesmo período, o uso de motores elétricos levou ao desenvolvimento da linha de montagem, o que permitiu que os bens de consumo duráveis fossem produzidos em grande escala e com custos cada vez menores. As grandes empresas passaram a adotar uma estrutura multidivisional, funcionando com uma equipe de gestores especializados em diversas funções, criando as estruturas hierárquicas compostas por departamentos (KERSTENETZKY, 1995); que representam uma estratégia de especialização e de redução do custo de obtenção e processamento das informações. Concomitantemente, surge o Taylorismo como principal escola de administração científica, com conceitos voltados para métodos de trabalho mais rápidos, mais eficientes e com instrumentos adequados. A mensuração e as técnicas estatísticas são incorporadas às práticas administrativas (CHANDLER, 1998a; 1998b; 1998c).

Outros autores da economia, ao escreverem sobre a firma, também influenciaram as disciplinas de administração; e a literatura decorrente foi classificada, não sem alguma arbitrariedade, como gerencial (managerial) ou comportamental (behavioral). As duas linhas têm como ponto de partida comum a recusa do princípio da maximização dos lucros como 
norma absoluta de decisão da firma. Na primeira linha, destaca-se Baumol (1959), e na segunda o expoente maior é Simon (1957), com seu princípio da racionalidade humana limitada. Ambas destacam aspectos e variáveis que devem ser tomados como relevantes nos processos de decisão em uma organização complexa como uma grande empresa, que opera sob incerteza e em mercados imperfeitos (FEIJÓ; VALENTE, 2004).

Pode-se observar que o acesso à informação e ao conhecimento se tornaram elementos fundamentais nas modernas teorias da firma, assim como as questões relacionadas às competências da firma. As disciplinas da administração foram afetadas por essas teorias, mas a maior razão da popularização da preocupação com a informação e o conhecimento na busca pela sobrevivência das organizações está relacionada com o novo paradigma tecnológico, baseado nas tecnologias de informação e comunicação (TICs), estabelecido no final do século XX e por muitos autores denominado terceira Revolução Industrial, centrada na microeletrônica (FREEMAN; LOUÇÃ, 2001).

$O$ efeito das TICs sobre as organizações foi intenso nos últimos 30 anos do século XX. Da mesma forma que a gestão científica de Taylor se desenvolveu no paradigma técnico-econômico da eletricidade e da linha de montagem, o paradigma da micro-eletrônica e das TICs trouxe em seu bojo novas prioridades e modelos de gestão (GABOR, 2001). Hoje, muitos anos após Drucker (1993) reconhecer que estamos vivendo na chamada 'Sociedade do Conhecimento', o modelo que mais se relaciona com essas mudanças tem sido denominado 'gestão do conhecimento'.

Esse modelo deve, então, ser analisado como resultado histórico da mudança tecnológica, à luz da moderna teoria da firma. Pavitt (2001) argumenta que, como resultado da importância crecente do conhecimento para sua competitividade, as empresas são cada vez menos autosuficientes, mais dependentes de fontes externas de conhecimento, e têm mais dificuldade em se organizarem internamente. A produção de conhecimentos cada vez mais especializados leva a saltos no desempenho do processo tecnológico, com efeitos potencialmente danosos para as práticas organizacionais estabelecidas. Portanto, grandes desafios estão colocados para a moderna administração.

\section{A gestão do conhecimento}

Ao longo do desenvolvimento do capitalismo, as grandes transformações vividas na organização das empresas têm colocado desafios para seus administradores. As empresas crescentemente diversificadas, operando em larga escala de produção e atendendo a mercados geograficamente diversificados, exigem controles cada vez maiores. O risco desses controles gerarem burocratização excessiva e falta de eficiência tem levado estudiosos e gestores a proporem novas formas de organizar.

A administração científica surgiu no contexto histórico de mudanças no início do século XX, com destaque para Frederick W. Taylor, e esta escola de administração ficou associada à priorização de fatores 
tecnológicos e das normas em detrimento dos fatores humanos. Como reação, desenvolveu-se a escola de relações humanas, que enxergou a empresa como sendo, predominantemente, uma organização social. Ambas as correntes têm preocupações ligadas à melhoria da eficiência nas organizações, mas lançam sobre elas olhares claramente distintos (GABOR, 2001).

Desde então, há um movimento pendular entre herdeiros dessas duas correntes, e "muitas idéias administrativas aparentemente obsoletas ressurgem, evoluindo e ganhando um lugar permanente na cultura da gestão. A reengenharia é a gestão científica reformulada para a era da informação" (GABOR, 2001, p. 11).

A escola das relações humanas, no final do século $X X$, era representada, entre outros, por W. Edwards Deming e Peter Senge, líderes do movimento em busca da qualidade e do enfoque da aprendizagem organizacional, desafiando os herdeiros da gestão científica nucleados em torno da reengenharia (GABOR, 2001): a gestão de pessoas na organização que aprende é uma resposta aos excessos da gestão científica associados à reengenharia. Dessa forma, repetindo-se o movimento pendular, a gestão humanista encontrava-se, no início do século XXI, na liderança e na busca por novos adeptos.

Observa-se, atualmente, a valorização na organização dos aspectos ligados ao aprendizado e ao conhecimento. Muitos dos enfoques e idéias propostos não abrem mão do uso de técnicas estatísticas e das tecnologias de informação e comunicação (TICs), desde que não se perca de vista o elemento humano. Um conjunto expressivo de soluções propostas pode ser agrupado sob a denominação de gestão do conhecimento.

De acordo com Hansen et al. (1999), a gestão do conhecimento desloca o foco da análise, dos fatores naturais e tangíveis para os ativos intelectuais, intangíveis em sua grande maioria. Segundo os autores, foi a consolidação do paradigma da microeletrônica, a partir de 1990, que estabeleceu as práticas conscientes de gestão do conhecimento, fortemente apoiadas nas tecnologias de informação e comunicação. Essas tecnologias tornam possível a codificação, o tratamento, a armazenagem, a recuperação e o compartilhamento da informação de forma mais fácil e barata do que em qualquer período anterior da história (HANSEN et al., 1999).

McKinley (2002) chama a atenção para o fato de que, apesar de a gestão do conhecimento não ter ainda se transformado num modelo comparável em escopo e profundidade ao taylorismo, ela adquire importância crescente para as empresas. Sem perder de vista que, como o próprio taylorismo, esses regimes são historicamente situados, o autor ressalta que muitos dos seus efeitos permanecem de forma duradoura.

A gestão do conhecimento coloca a questão sobre a possibilidade de se gerir o conhecimento. Alguns autores consideram que esta prática é perfeitamente possível e, mais do que isso, é necessária dentro da dinâmica organizacional. Outros consideram a expressão 'gestão do conhecimento' um oxímoro, isto é, uma figura de retórica em que se 
combinam palavras de sentido oposto, que parecem excluir-se mutuamente, mas que, no contexto, reforçam a expressão, como, por exemplo, obscura claridade ou música silenciosa, pois não se pode administrar um ativo que reside nas mentes dos empregados e que é compartilhado, basicamente, por meio de conversação. O que se pode fazer é gerenciar o ambiente no qual o conhecimento é criado, descoberto, capturado, compartilhado, filtrado, validado, transferido, adotado, adaptado e aplicado, para se criar valor. Porém, estes mesmos autores reconhecem que, embora o conhecimento não possa ser gerido, a denominação gestão do conhecimento ganhou reconhecimento público e engloba avanços na gestão de sistemas de informação e de pessoas.

Segundo Anklan (2002, p. 8, tradução nossa), "a gestão do conhecimento é uma densa rede de temas oriundos de diversas disciplinas". Para ele, os autores que definiram o campo e introduziram essa denominação foram Laurence Prusak e Thomas Davenport, junto com Thomas Stewart e Carla O’Dell.

Stewart (1998) se refere à gestão do conhecimento como uma das mais importantes mudanças ocorridas no cenário econômico mundial, decorrente da transição da era industrial para a do conhecimento, ao final do século $X X$. Segundo ele, no processo de geração de valor, a importância da matéria-prima se reduz face ao aumento da importância do uso da informação e do conhecimento. A informação passa, então, a ser a base do processo de geração de novos conhecimentos, e estes exercem a função de mola propulsora do crescimento econômico, sendo reconhecidos como recurso fundamental.

$\mathrm{Na}$ visão de Stewart (1998), a gestão do conhecimento se dá através de sua mensuração e valorização, considerando-se sua relevância para as organizações. Sem o gerenciamento estratégico do conhecimento, estas não se mantêm competitivas.

Uma dificuldade adicional para a compreensão do conteúdo da gestão do conhecimento está na própria definição do que seria conhecimento. Este está intrinsecamente associado aos indivíduos; e a criação de novos conhecimentos é um processo que ocorre em suas mentes. No entanto, o objetivo da gestão do conhecimento é atuar sobre o conhecimento organizacional, isto é, aquele criado e compartilhado dinamicamente pela interação social entre os indivíduos da organização. Este inclui as rotinas existentes, as memórias externas aos indivíduos (arquivos, manuais, normas, ou seja, o conhecimento codificado) e os conhecimentos mantidos nas equipes da organização (NELSON; WINTER, 1982). Conseqüentemente, $\ldots$.

... ver a memória da organização como redutível às memórias de seus membros individuais é negligenciar, ou subestimar, a ligação entre essas memórias individuais pelas experiências compartilhadas no passado, experiências essas que estabeleceram o extremamente detalhado e específico sistema de comunicações que suporta o desempenho das rotinas (NELSON, WINTER, 1982, p. 105, tradução nossa). 
Depreende-se daí que os sistemas de informação e comunicação são apenas parcialmente formais, isto é, baseados em dispositivos, aplicativos e normas formais, devendo contar também com a comunicação informal para o desempenho das rotinas.

Embora o conhecimento organizacional esteja em grande parte armazenado na organização, muitos autores terminam por enfatizar os aspectos ligados ao conhecimento tácito dos membros da organização, como, por exemplo, Nonaka e Takeuchi (1998), que afirmam ser esse o tipo de conhecimento mais importante.

Por outro lado, diversos autores (NONAKA; TAKEUCHI, 1998; CHOO, 1998; DAVENPORT; PRUSAK, 1998; HANSEN et al., 1999) defendem a tese de que a gestão do conhecimento está ligada, de forma indissociável, à gestão de pessoas, e que o uso das TICs e das práticas gerenciais é relevante para a criação de um ambiente adequado ao compartilhamento da informação e do conhecimento.

Um exemplo do que foi mencionado acima pode ser encontrado na seção de gestão do conhecimento (knowledge management) do portal da 12Manage (12MANAGER, 2006). Esse portal é amplamente utilizado e facilmente encontrado pelas ferramentas de busca. Apresenta um resumo dos principais métodos gerenciais (cerca de 400) classificados em 12 disciplinas gerenciais e um glossário com cerca de 1500 termos da área de administração. Os termos do glossário estão apoiados em livros e trabalhos de autores da área, e os de gestão do conhecimento estão baseados no livro de Collison e Parcell (2001).

Alguns trabalhos acadêmicos feitos no Brasil apontam, em linhas gerais, para os mesmos aspectos discutidos até aqui.

Nehmy (2000) analisa a gestão do conhecimento, destacando sua posição na história dos modelos organizacionais e da produção, assinalando que o seu avanço foi decorrente da conjunção de avanços da tecnologia de informação e de reação aos processos da reengenharia. Segundo ela, a gestão do conhecimento, ao enfocar os aspectos humanos, pretende, de fato, gerenciar "aquilo que não foi apropriado pela tecnologia ou não foi codificado, mantendo-se submerso no processo de trabalho $[\ldots]^{\prime \prime}$ (NEHMY, 2000, p. 84).

A autora associa a gestão do conhecimento à tentativa de incorporar todo o conhecimento tácito ao patrimônio da empresa. Dessa forma, trata-se de uma técnica que visa se apropriar do conhecimento dos trabalhadores. Nehmy (2000) conclui que a gestão do conhecimento se compõe de um conjunto de processos apoiados nas TICs, que, embora permitam e incentivem a criação de novos conhecimentos entre os membros da organização, têm como objetivo final a incorporação de todo o conhecimento ao patrimônio da empresa, ou seja, a desqualificação do seu próprio conjunto de trabalhadores, mesmo aqueles ligados à criação de conhecimentos.

Para Cianconi (2003), a gestão do conhecimento seria um conjunto de ações sistemáticas utilizadas para facilitar o compartilhamento do conhecimento por meio de políticas, metodologias e tecnologias adequadas. A autora chama, também, a atenção para o fato de que o 
termo gestão do conhecimento, embora seja amplamente empregado, é inadequado, e deve ser encarado como uma metáfora, "uma vez que o conhecimento é inerente ao ser humano e não se transfere diretamente" (CIANCONI, 2003, p. 16). As técnicas de gestão do conhecimento servem para estimular o aprendizado, o compartilhamento e o registro do conhecimento; e "uma vez codificado o conhecimento, este se torna informação em potencial, passível, esta sim, de ser gerenciada" (CIANCONI, 2003, p. 16). A gestão do conhecimento seria uma forma de ir além da mera gestão da "informação formal, registrada, passando ao mundo mais difuso dos ativos intangíveis, aos canais informais de comunicação e ao chamado capital intelectual" (CIANCONI, 2003, p. 90). Assim, as ações de gestão do conhecimento lidam com os aspectos humanos das organizações e com o conhecimento tácito dos indivíduos, o que representa um avanço em relação à gestão da informação.

As ações de GC, para serem efetivas, necessitam de outras condições, como políticas de motivação, valorização da confiança, papel de liderança das chefias, dentre outras. Concluindo, a autora constata que a GC é, além de uma metáfora, um guarda-chuva que abriga inúmeras práticas mais voltadas para a gestão da informação, da comunicação e das tecnologias de informação, e que "o discernimento e entendimento das duas entidades (informação e conhecimento) é fundamental para os resultados positivos dos programas de Gestão do Conhecimento" (CIANCONI, 2003, p. 252).

A confusão entre práticas de gestão da informação e do conhecimento também foi destacada por Alvarenga Neto (2002). O autor coloca que uma etapa necessária para "quaisquer outras iniciativas de Gestão do Conhecimento" (ALVARENGA NETO, 2002, p. 151) passa por uma definição clara desses conceitos.

\section{Novas tecnologias, limites da firma e gestão do conhecimento}

As tecnologias de informação e comunicação (TICs) afetam os processos de coordenação e integração da firma (conforme apresentados por Teece (2005), pois atingem, inclusive, seus limites. Essas tecnologias afetam os custos de transação e as práticas de externalização do conhecimento, mudando as configurações das redes internas (de indivíduos e de estruturas, como, por exemplo, departamentos) e externas (entre organizações) (WILLIAMSON, 1995).

Segundo Bender (2002), os limites da firma vêm sendo, constantemente, desafiados. As mudanças nos tipos de transação e em seu ambiente são em grande parte fruto das novas TICs, que permitem aperfeiçoar, por exemplo, a gestão da subcontratação vertical (vertical outsourcing), isto é, as parcelas da cadeia de valor à montante (fornecedores de insumos) e à jusante (canais de distribuição). Empresas 
que já foram exemplos de verticalização dedicam-se, agora, à sua atividade principal, e as divisões que forneciam insumos são transformadas em empresas independentes, funcionando em rede. As modernas corporações têm procurado se livrar das atividades periféricas, concentrando-se em suas atividades básicas (core capabilities) (FEIJÓ; VALENTE, 2004).

Citando pesquisas na área, Bender (2002) aponta que as TICs afetam tanto as transações internas quantos as transações externas às firmas. Segundo essas pesquisas, inicialmente os impactos foram maiores nas transações internas, com a introdução de aplicativos de gestão de recursos das empresas (enterprise resource planning (ERP) software). Porém, em seguida, novas formas e recursos das TICs (como a Internet e os sistemas de informação interorganizacionais) levaram a um maior relacionamento interorganizacional e permitiram maiores ganhos de produtividade nas relações mercantis entre diferentes empresas. Ou seja, essas tecnologias reduziram, inicialmente, os custos internos de transação, para, em seguida, reduzir os custos de transação externos.

Essa redução dos custos de transação tem impacto na estrutura das empresas, pois as TICs permitem uma melhor gestão da escolha entre produzir internamente ou comprar fora, ou seja, elas diminuem os custos de transação, fixos e variáveis, referentes à coordenação das atividades econômicas. Em sua conclusão, baseada em ampla pesquisa empírica, Bender (2002) confirma que as fronteiras das firmas foram afetadas pela difusão dessas tecnologias, favorecendo as empresas menores e mais voltadas para o seu negócio principal (core capabilities), pois as TICs possibilitam o aumento coordenado do número de parceiros pelo seu amplo potencial de controle de informações e processos.

Como conseqüência, os limites entre firma e mercado passam a levar em conta modos cooperativos intermediários de relações, favorecendo o florescimento de redes. As redes são um novo tipo de organização que surge como resposta à crescente incerteza, ao aumento do risco e do custo de processamento de informações. As empresas procuram relações mais colaborativas, envolvendo cooperação e confiança, e as TICs ampliam os limites das redes de empresas (FEIJÓ; VALENTE, 2004).

Nesse contexto, cada vez mais a GC tem que ser adaptada a um ambiente mais amplo, que envolva toda a cadeia produtiva e as organizações de apoio ao negócio. Novamente, uma base teórica construída sobre a Teoria da Firma certamente facilitará melhor compreensão e preparação dessas transformações.

\section{Conclusão}

Resumindo as discussões apresentadas, este artigo iniciou-se com a breve apresentação da teoria da firma, conforme as principais correntes da ciência econômica. Destacou-se a crítica à visão neoclássica da firma e a incorporação de elementos mais próximos à realidade, como os conceitos de custos de transação, que se relacionam, dentre outros 
aspectos, com os custos associados à busca e ao processamento da informação, com a racionalidade limitada dos indivíduos, com a necessidade de trabalho em equipe e com o papel das rotinas e do conhecimento tácito na constituição das competências das firmas.

Esses aspectos tratados pela teoria econômica afetaram as disciplinas de administração e a sua forma de entender o ambiente interno das organizações. Essas mudanças nas disciplinas de administração foram reforçadas pela incorporação, em grande escala, das modernas TICs aos processos administrativos. Hoje, fala-se que os negócios e a sociedade em geral estão no meio de uma revolução tecnológica, que se realiza em torno das TICs e que transforma o uso das informações nas empresas. Essa transformação afeta as práticas de gestão, fenômeno semelhante ao que ocorreu no final do Século XIX e que resultou em mudanças profundas nas práticas gerenciais, gerando aquelas que hoje são amplamente conhecidas.

As práticas de Gestão do Conhecimento (GC) podem ser, hoje em dia, consideradas como parte de uma nova ideologia de gestão, ainda que não dominante. Nelas, há o reconhecimento do papel relevante das TICs nos processos de criação de conhecimento no interior das empresas, incluindo a geração de inovações, sem perder de vista a relevância do ser humano e a importância do conhecimento tácito. No entanto, uma compreensão mais abrangente do comportamento das firmas, apoiada numa base teórica mais sólida, seria importante para a compreensão do alcance da GC. Outros autores exprimem a mesma opinião em relação à Gestão da Inovação, evidenciando a importância da teoria na análise dessas práticas de gestão.

Da mesma forma que as TICs facilitam as práticas de criação de conhecimento nas empresas, elas abrem possibilidades de ampliação do espaço de cooperação entre diferentes organizações. As redes assim criadas afetam os limites da firma, pois mudam os parâmetros para a decisão entre o que fazer internamente e o que comprar de fornecedores. Abrem-se, também, novos espaços para a aplicação da Gestão do Conhecimento.

Como desdobramento, a discussão sobre a essência e a natureza da firma traz a inovação para o centro dos debates sobre a teoria da firma. Com isso, a associação entre conhecimento e inovação torna-se mais evidente, aproximando a reflexão sobre a Gestão do Conhecimento daquela sobre a Gestão da Inovação.

\section{Referências}

12MANAGER (Holanda). Knowledge management: management knowledge portal. Disponível em: <http://www.12manage.com>. Acesso em: 10 abr. 2006.

ANKLAN, P. Knowledge management: the collaboration thread. Bulletin of the american socienty for information science and technology, v. 28, n. 6, p.8-11, ago./set. 2002. 
ALVARENGA NETO, R. C. D. Gestão da informação e do conhecimento nas organizações: análise de casos relatados em organizações públicas e privadas. 2002. 235 f. Dissertação (Mestrado em Ciência da Informação) Escola de Ciência da Informação, Universidade Federal de Minas Gerais, Belo Horizonte, 2002.

BAUMOL, W. J. Business Behavior: value and growth. Nova York: MacMillan, 1959.

BENDER, C. The theory of the firm revisited: changing firm boundaries in a new information and communication environment. Germany: University of Muenster, 2002. Mimeo. Disponível em <http://www.isnie.org/ISNIE02/Papers02/bender.pdf>. Acesso em: 10 abr. 2006.

CHANDLER, A. D. Os primórdios da "grande empresa" na indústria norteamericana. In: McCRAW, T. K. Alfred Chandler: ensaios para uma teoria histórica da grande empresa. Rio de Janeiro: Fundação Getúlio Vargas, 1998a. p. 35-66.

. Desenvolvimento, diversificação e descentralização. In: McCRAW, T. K. Alfred Chandler: ensaios para uma teoria histórica da grande empresa. Rio de Janeiro: Editora Fundação Getúlio Vargas, 1998b. p .68118.

. Introdução a strategy and sctructure. In: McCRAW, T. K. Alfred Chandler: ensaios para uma teoria histórica da grande empresa. Rio de Janeiro: Editora Fundação Getúlio Vargas, 1998c. p. 121-140.

$\mathrm{CHOO}$, C. W. The knowing organization: how organizations use information to construct meaning, create knowledge, and make decisions. New York: Oxford University Press, 1998.

CIANCONI, R. B. Gestão do conhecimento: visão de indivíduos e organizações no Brasil. 2003. 287f. Tese (Doutorado em Ciência da Informação) - Instituto Brasileiro de Informaçãom em Ciência e Tecnologia/Universidade Federal do Rio de Janeiro, Rio de Janeiro, 2003.

COASE, R. H. The institutional structure of production. The Nobel Foundation, $1991 . \quad$ Disponível em: <http://nobelprize.org/economics/laureates/1991/coase-lecture.html >. Acesso em: 18 nov. 2004.

COASE, R. The nature of the firm. Economica; London School of Economics and Political Science (LSE), Suntory and Toyota International Centres for Economics and Related Disciplines (STICERD), p. 386-405, nov. 1937.

COELHO, A. L. A. L.; PAVÂO, Y. M. P.; BANDEIRA-DE-MELLO, R. A produção científica direcionada à Visão Baseada em Recursos (ResourceBased View - RBV) no Brasil e no exterior. Revista Brasileira de Docência, Ensino e Pesquisa em Administração. Cristalina, Goiás, n. esp., v. 1, n. 2, p.177-207, Julho/2009. 
COLLISON, C.; PARCELL, G. Learning to fly: practical lessons from one of the world. Milford, EUA: Capstone Publishing, Inc., 2001. 240 p.

DAVENPORT, T. H.; PRUSAK, L. Conhecimento empresarial: como as organizações gerenciam o seu capital intelectual. Rio de Janeiro: Campus, 1998.

DeBRESSON, C. An entrepreneur cannot innovate alone: networks of entreprises are required. In: DRUID CONFERENCE ON SYSTEMS OF INNOVATION, 1999, Denmark. Paper. Denmark: Aalborg, 1999. Disponível em: <http://www.druid.dk/conferences/summer1999/confpapers/debresson.pdf>. Acesso em: 20 set. 2004.

(Ed.). Economic interdependency and innovative activity: an input-output analysis. Cheltenham, England: Edward Elgar, 1996.

DRUKER, P. Sociedade pós-capitalista. São Paulo: Pioneira, 1993.

FEIJÓ, C. A.; VALENTE, É. A firma na teoria econômica e como unidade de investigação estatística: evolução nas conceituações. Revista de Economia Contemporânea. Rio de Janeiro, v. 8, n. 2, p. 351-376, jul./dez. 2004.

FREEMAN, C.; LOUÇÃ, F. As time goes by: from the industrial revolution to the information revolution. Oxford: The Oxford University Press, 2001. $407 \mathrm{p}$

GABOR, A. Os filósofos do capitalismo: a genialidade dos homens que construiram o mundo dos negócios. Rio de Janeiro: Campus, 2001. 430 p.

GRANOVETTER, M. Business Groups. In: SMELSER, N. J.; SWEDBERG, R. (Eds.). The handbook of economic sociology. N.J.: Princeton University Press, 1994.

HANSEN, M. et al. What's your strategy for managing knowledge. Harvard business review, [S.I], Mar./Apr., 1999.

KERSTENETZKY, J. Firmas e mercados: uma análise histórico-institucional do problema da coordenação. 178f. Tese (Doutorado) - Departamento de Economia, UFRJ, Rio de Janeiro, 1995.

KNIGHT, F. Risk, uncertainty and profit. Chicago: Chicago University Pres, 1971 apud KERSTENETZKY, J. Firmas e mercados: uma análise históricoinstitucional do problema da coordenação. 178f. Tese (Doutorado) Departamento de Economia, UFRJ, Rio de Janeiro, 1995.

LAKATOS, I. O falseamento e a metodologia dos programas de pesquisa científica. In: LAKATOS; MUSGRAVE (Orgs.). A crítica e o desenvolvimento do conhecimento. São Paulo: Cultrix-Usp, 1979.

MARINS, L. M. Economia, tecnologia e inovação: da teoria da firma à gestão da inovação tecnológica. Revista Eletrônica de Ciência Administrativa. Campo Largo - PR, v. 6, n. 1, maio/2007. Disponível em: $<$ http://revistas.facecla.com.br/index.php/recadm/article/view/250/159>. Acesso em: 20 jun. 2009. 
MARSHALL, A. Princípios de economia: tratado introdutório. São Paulo: Abril Cultural, 1982. 2 v.

McKINLEY, A. The limits of knowledge management. New technology, Work and Employment, v.17, n.2, p. 76-88, 2002.

NEHMY, R. M. Q. O ideal do conhecimento codificado na era da informação: o programa de gestão do conhecimento. 2000. 213f. Tese (Doutorado em Ciência da Informacao) - Escola de Ciência da Informação, UFMG, Belo Horizonte, 2000.

NELSON, R. R; WINTER, S. G. Economic change: an evolutionary theory of economic change. Cambridge, Mass.: [s.n.], 1982.

NEWELL, A.; SHAW, J. C.; SIMON, H. A. The process of creative thinking. In: GRUBER, H. E.; TERREL, G.; WERTHEIMER, M. (Comp.). Contemporary approaches to creative thinking. New York: Artherton Press, 1962 apud NELSON, R. R; WINTER, S. G. Economic change: an evolutionary theory of economic change. Cambridge, Mass.: [s.n.], 1982.

NONAKA, I. ; TAKEUCHI, H. Criação de conhecimento na empresa: como as empresas japonesas geram a dinâmica da inovação. Rio de Janeiro: Campus, 1998.

PAVITT, K. Can the large penrosian firm cope with the dynamics of technology? Science and technology policy research: eletronic working paper series, n. 68, p. 1-18, sep. 2001.

PENROSE, E. T. The theory of the growth of the firm. Oxford: Oxford Basil Blackwell, 1959.

PITELIS, C. N, TEECE, D. J. The (new) nature and essence of the firm. European Management Review. v. 6, n. 1, p. 5-15, 2009.

RICHARDSON, G. B. The organization of industry. The Economic Journal. v; 82, p. 883-896, 1972 apud KERSTENETZKY, J. Firmas e mercados: uma análise histórico-institucional do problema da coordenação. 178f. Tese (Doutorado) - Departamento de Economia, UFRJ, Rio de Janeiro, 1995.

SILVA, Antonio Braz de Oliveira e. O cluster da construção em Minas Gerais e as práticas de colaboração e de gestão do conhecimento: um estudo das empresas da Região Metropolitana de Belo Horizonte (MG). 2007. 419f. Tese (Doutorado). ECI/UFMG, Belo Horizonte:, 2007.

SIMON, H. A. Administrative behavior: a study of decision-making processes in administrative organization. 2. ed. New York: Free Press, 1957. 259p.

STEWART, T. A. Capital intelectual: a nova vantagem competitiva das empresas. Rio de Janeiro: Campus, 1998.

WILLIAMSON, O. E. (Comp.). Organization theory: from Chester Barnard to the present and beyond. New York, Oxford: Oxford University Press, 1995. 
WILLIAMSON, O. E. Markets and hierarchies: analysis and antitrust implications: a study in the economics of internal organization. New York: Free Press, 1975. 286 p. v.8. 